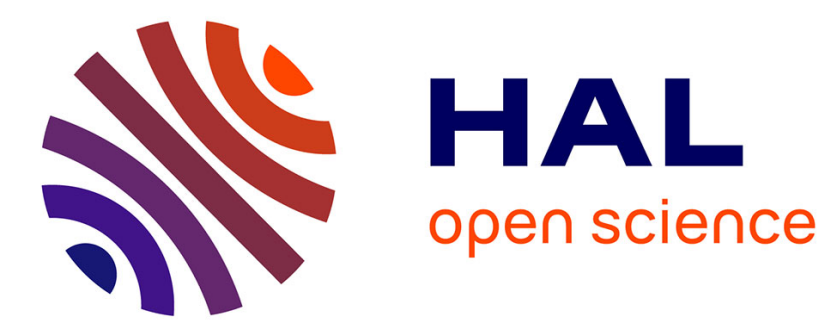

\title{
Chemoselective olefin metathesis transformations mediated by ruthenium complexes
}

\author{
Steven P Nolan, Hervé Clavier
}

\section{To cite this version:}

Steven P Nolan, Hervé Clavier. Chemoselective olefin metathesis transformations mediated by ruthenium complexes. Chemical Society Reviews, 2010, 10.1039/b912410c . hal-01409772

\section{HAL Id: hal-01409772 \\ https://hal.science/hal-01409772}

Submitted on 6 Dec 2016

HAL is a multi-disciplinary open access archive for the deposit and dissemination of scientific research documents, whether they are published or not. The documents may come from teaching and research institutions in France or abroad, or from public or private research centers.
L'archive ouverte pluridisciplinaire HAL, est destinée au dépôt et à la diffusion de documents scientifiques de niveau recherche, publiés ou non, émanant des établissements d'enseignement et de recherche français ou étrangers, des laboratoires publics ou privés.

\section{(1) (1) $\$$}

Distributed under a Creative Commons Attribution - NonCommercial - NoDerivatives| 4.0 


\title{
Chemoselective Olefin Metathesis Transformations Mediated by Ruthenium Complexes
}

\author{
Steven P. Nolan ${ }^{* a}$ and Hervé Clavier* ${ }^{b}$ \\ Received (in $X X X, X X X)$ Xth $X X X X X X X X X 200 X$, Accepted Xth $X X X X X X X X X 200 X$ \\ ${ }_{5}$ First published on the web $X$ th $X X X X X X X X X 200 X$ \\ DOI: 10.1039/b000000x
}

Over the past decade, ruthenium-mediated metathesis transformations, including polymerization reactions, cross-metathesis, ring-closing metathesis, enyne metathesis, ring-rearrangement metathesis, and also tandem processes, represent one of the most 10 studied families of organic reactions. This has translated into the development of a large number of structurally diverse catalysts. Whereas, most of these investigations are focused on determining catalytic performance, only rare examples of studies dealing with chemoselectivity have been reported to date. Usually, variations are observed in product conversions but rarely in product distributions. Herein, we provide an overview of the 15 stereochemistry of newly formed $\mathrm{C}=\mathrm{C}$ bond either in ring-closing or cross-metathesis as a function of the catalyst structure. A discussion of disparities encountered in macrocyclisation reactions leading (or not) to the formation of dimeric products is also presented. Since distinctive metathesis products could be isolated as a function of the ligand borne by the ruthenium centre - phosphine or N-heterocyclic carbene - in the ${ }_{20}$ dissymetrization of trienes, enyne metathesis and ring rearrangements, these topics are also discussed.

\section{Introduction}

Olefin metathesis represents one of the most powerful and attractive tools in polymer science and organic synthesis for 25 the formation of carbon-carbon double bonds. ${ }^{1}$ The spectacular improvements in this reaction achieved over the last two decades are quite familiar to most chemists since a number of these catalysts, able to perform a plethora of olefin metathesis reactions, are commercially available. ${ }^{2}$ The 30 popularity of the method is also due to the numerous types of metathesis transformations that have been developed, for example, ring-closing metathesis (RCM), ${ }^{3}$ enyne $\mathrm{RCM},{ }^{4}$ cross metathesis $(\mathrm{CM}),{ }^{5}$ ring-rearrangement metathesis (RRM), ${ }^{6}$ or ring-opening polymerization metathesis (ROMP). ${ }^{7}$ Thus, with

35 the same metal-carbene complex, several reactions can be achieved depending on the substrates and reaction conditions. For these reasons, the development of catalytic systems, ever more active in metathesis transformations, is still a field of intensive research. ${ }^{8}$ The rapid progresses in this area have 40 been punctuated by groundbreaking developments particularly focusing on well-defined ruthenium-carbene complexes, such as the highly tolerant to functional group rutheniumbenzylidene Cat-1A by Grubbs in 1995 (Figure 1). ${ }^{9}$ In 1999, other ruthenium-alkylidene complexes were discovered: $\mathrm{Ru}-$ 45 indenylidene $^{10}$ and Ru-isoproxybenzylidene, ${ }^{11}$ namely the Hoveyda catalyst. At the same time, substitution of a tertiary phosphine by an $\mathrm{N}$-heterocyclic carbene (NHC) ligand led to the emergence of second generation complexes displaying enhanced catalytic performances, catalysts such as Cat-1B ${ }^{12}$ 50 and Cat-1C. ${ }^{13}$ Since then, systematic derivatisation has been carried out on benzylidene-, ${ }^{14}$ indenylidene- ${ }^{15}$ and isopropoxybenzylidene-catalysts ${ }^{16}$ playing on phosphine, ${ }^{17}$
NHC,${ }^{18}$ pyridine adducts, ${ }^{19}$ or anionic ligands, ${ }^{20}$ as well as the development of supported catalysts. ${ }^{21}$ This has translated into 55 a large number of ruthenium-based complexes, which are occasionally compared to each other mainly in terms of efficiency. ${ }^{22}$ Nonetheless, several reports have demonstrated that catalyst structure could also influence the distribution of metathesis products, i.e. the chemoselectivity.
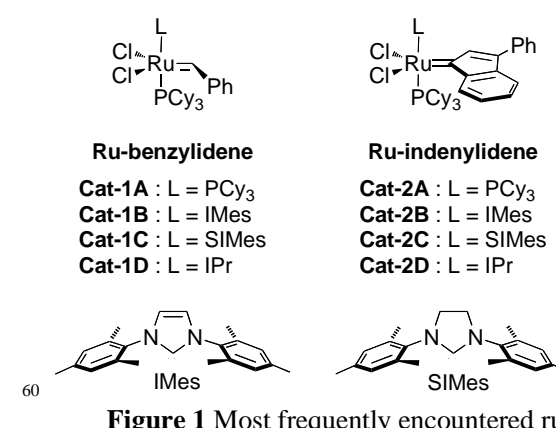

Cat-2B : $L=$ IMes

Cat-2C : $L=$ SIMes

Cat-2D : $L=I P r$

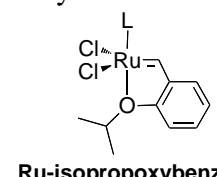

Ru-isopropoxybenzylidene

Cat-3A : $L=\mathrm{PCy}_{3}$

Cat-3B : $L=$ IMes

Cat-3C : $L=$ SIMes
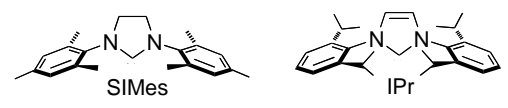

Figure 1 Most frequently encountered ruthenium complexes for metathesis transformations

Here, we propose to provide a critical overview of chemoselectivity in ring-closing metathesis of dienes and 65 enynes, ring-rearrangement metathesis and cross metathesis as a function of the catalyst employed. Even if reactivity differences are usually reported between $1^{\text {st }}$ and $2^{\text {nd }}$ generation complexes, several other parameters have proven to affect chemoselectivity. Of note, this review focuses on commonly 70 employed ruthenium-mediated olefin metathesis since tungsten- or molybdenum-based complexes are scarcely investigated. For the Reader's convenience, the structures of the most frequently encountered ruthenium catalysts are presented in Figure 1. 


\section{Ring-Closing Metathesis of Alkenes}

\subsection{RCM of compounds with multiple $\mathrm{C}-\mathrm{C}$ double bonds}

Over the past few years, it has been demonstrated that RCM reactions involving more than two $\mathrm{C}-\mathrm{C}$ multiple bonds 5 presented interesting opportunities for the construction of functionalized heterocycles. ${ }^{23}$ In 2000, Schmidt reported a rare example of comparison between benzylidene- and indenylidene-based catalysts for RCM of polyalkene substrate 1. ${ }^{24}$ Mediated by pre-catalyst Cat-1A, metathesis reaction led 10 to the formation of the spiro product $\mathbf{2}$ in low yield due to the competition with intermolecular metathesis (Scheme 1). On the other hand, the $1^{\text {st }}$ generation indenylidene complex Cat2A was also evaluated; the double RCM sequence did not occur and only the dihydropyran $\mathbf{3}$ was isolated in poor yield.

15 The formation of $\mathbf{3}$ can be explained by a succession of RCM reaction, sequential double bond isomerization, and then Claisen rearrangement. Unfortunately considering the low yields of $\mathbf{2}$ and $\mathbf{3}$, this example is not entirely pertinent. Moreover, the reactivity of $\mathbf{1}$ was not investigated further and 20 no details were given as to the cause of this difference in reaction behavior: the nature of the ruthenium complex or reaction conditions (temperature or solvent).

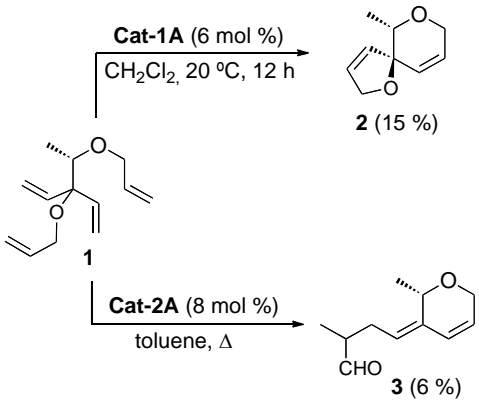

Scheme 1 Ring-closing metathesis of polyalkene 1 with indenylidene ruthenium-based catalysts

As a part of a reaction scope investigating novel polymersupported ruthenium olefin metathesis catalysts, Nolan and co-workers have examined acyclic tetraenes such as $\mathbf{4}$ for the preparation of bicyclic compounds. ${ }^{25}$ In addition to polymers, 30 several products were obtained, resulting from competition between a single RCM affording cycloalkane 7 and two RCM steps leading to bis-heterocycle 5; 6 coming from a mono $\mathrm{RCM}$ involving an O-allyl moiety (Scheme 2). Due to the reversibility of olefin metathesis, cycloalkene 7 can be 35 converted into the more thermodynamically stable bicyclic compound 5. Several complexes were used to carry out this study: Cat-1A, Cat-1B, Cat-1C, as well as their immobilized polymer-supported analogues. Unfortunately, these catalysts were tested under different reaction conditions (solvent and 40 temperature), thus the differences observed in product distribution cannot be unambigously attributed to the complex itself. Moreover, in the case of recycling, some chemodivergence has been noted between two consecutive runs, and could be explained by the loss of activity during the 45 recycling process.

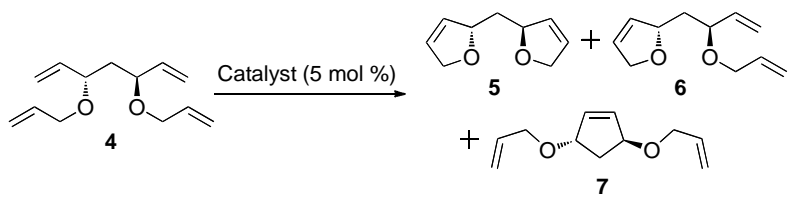

Scheme 2 Ring-closing metathesis of acyclic tetraene 4

Taking advantage of the activity difference between catalysts, it has been possible to perform chemoselective metathesis 50 transformation. Wallace investigated diastereoselective double RCM reaction exploiting the unique characteristics of the catalyst. $^{26}$ Treatment of tetraene $\mathbf{8}$ with Hoveyda-Grubbs catalyst Cat-3C led to ca. $50 \%$ of the spirocyclic product 9 with only poor diastereoselectivity (Scheme 3 ). In spite of the 55 use of ethylene, formation of significant amounts of byproducts was observed due the high catalytic activity of Cat3C. Conversely, the less active Ru-indenylidene complex Cat-2A gave cleanly and quantitatively the monocyclised product 10 with good diastereoselectivity $(86 \% \mathrm{dr})$. The 60 second RCM leading to the spiro compound $\mathbf{9}$ was achieved with the more active complex Cat-3C. Wallace reported as well an analogue example but involving a quadruple RCM for which the stereoselectivity depends of the catalyst used. ${ }^{27}$

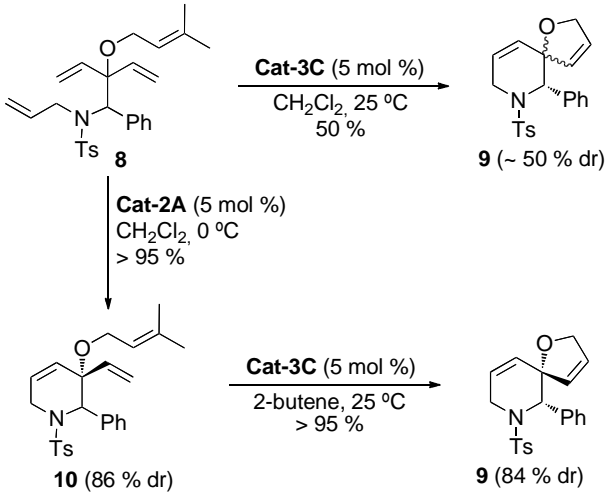

65 Scheme 3 Diastereoselective double ring-closing metathesis reaction

Dissymetrization of prochiral trienes is the most frequently encountered enantioselective metathesis reaction. ${ }^{1 \mathrm{e}, 28}$ During the course of a study aimed at designing and synthesizing new chiral NHC ligands for asymmetric ring-closing metathesis, ${ }^{29}$ 70 Grubbs and co-workers observed that RCM product distribution could be related to the structure of the NHC ligand (Scheme 4). ${ }^{30}$ Usually, metathesis catalysts enable RCM between the most activated olefins, i.e. for which the steric hindrance is least important. Therefore, in the case of 75 substrate 11, catalysts such as Cat-3C formed only 7membered ring 12. The strategy for the chiral induction developed by Grubbs is based on a transfer of stereochemistry from the chirality of the backbone to the $\mathrm{N}$-substituents of the NHC that are dissymmetric and sterically less bulky. Cat-1E 80 bearing a less sterically hindered NHC catalyzed the RCM of 11, however with this complex significant amount of the unfavored 5-membered ring $\mathbf{1 3}$ was observed. Less bulky NHC containing complexes are more reactive towards hindered C-C double bonds. From this observation, several 85 catalysts have been developed for the formation of tetrasubstituted olefins by $\mathrm{RCM}^{30,31}$ and tetrasubstituted C-C 
double bond by $\mathrm{CM}^{32}$ This example clearly showed that the NHC congestion can influence the outcome of a metathesis transformation.

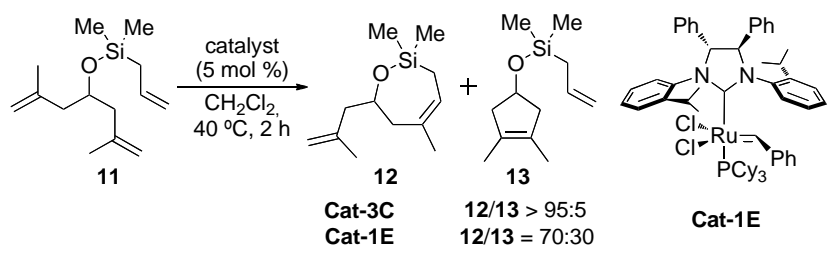

Scheme 4 Ring-closing metathesis: dissymetrisation of triene

\subsection{Cyclisation versus dimerisation and oligomerisation}

As often is the case in cyclisation processes, metathesis byproducts such as dimers, oligomers and polymers are observed in significant amounts when the size of the targeted ring 10 increases. Thermodynamically, the formation of 5- and 6membered rings is greatly favored, however, for rings larger than 8, problems are encountered. Reaction mixtures in high dilution are generally used to circumvent the formation of these by-products. Although barely exploited, structure of the 15 catalyst used can play a significant role. Recently, Percy surveyed the synthesis of difluorinated pentopyranose analogues involving the formation of 8 -membered ring 15 by $\mathrm{RCM}^{33}$ Diene 14 was cyclised into 15 in good yield using $2^{\text {nd }}$ generation Grubbs catalyst Cat-1C and $\mathrm{Ti}(\mathrm{O} i \mathrm{Pr})_{4}$ as co20 catalyst (Scheme 5). On the other hand, when the indenylidene catalyst Cat-2A was used only traces of the expected product 15 (4\%) were observed, mass balance accounting for noticeable quantities of dimer $\mathbf{1 6}$. Unfortunately, in this case the reactivity difference between

${ }_{25}$ Cat-1C and Cat-2A is not clear as the role of the co-catalyst $\mathrm{Ti}(\mathrm{O} i \mathrm{Pr})_{4}$ has not been established.

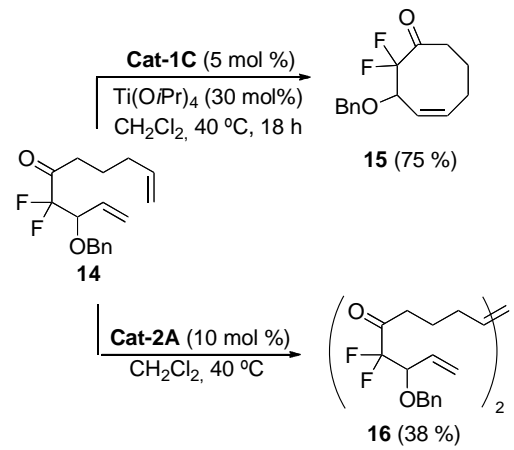

Scheme 5 Formation of 8 -membered ring by RCM

A different example showed that $1^{\text {st }}$ generation catalysts are 30 more favourable to dimerisation than those bearing a NHC ligand. The macrocyclisation of trisubstituted diene $\mathbf{1 7}$ led to the formation of dimer 19 in the presence of catalyst Cat-1A (Table 1$).^{34}$ Thus the activity of $\left(\mathrm{PCy}_{3}\right)_{2}$-containing complexes is related to the steric bulk of the substrate; whereas for RCM 35 giving rise to small rings, trisubstituted dienes are tolerated and only RCM of disubstituted diene is possible for larger rings. Second generation complexes Cat-1B-D displayed superior reactivity and the 14-membered ring $\mathbf{1 8}$ was isolated in acceptable yields for all catalysts. Nonetheless, a study of 40 the reaction profile demonstrated that $\mathbf{1 8}$ is not only obtained by direct RCM of $\mathbf{1 7}$ but $\mathbf{1 9}$ is also a reaction intermediate.
Table 1 Comparison of catalyst activity in macrocyclisation

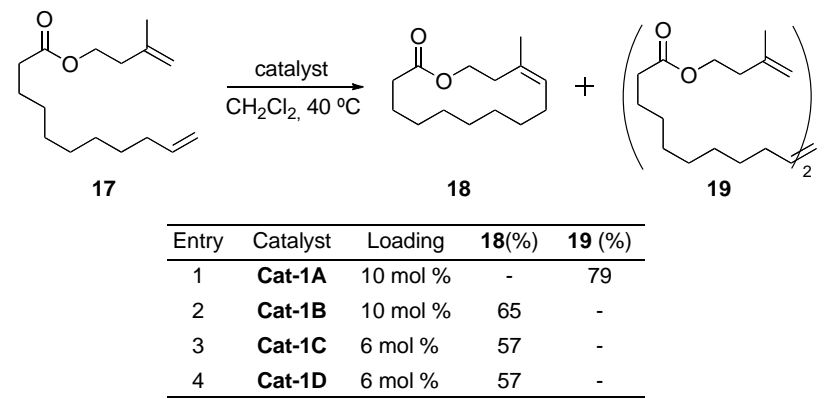

Subsequent to the development of $2^{\text {nd }}$ generation catalyst Cat45 1C, Grubbs investigated the performance of this catalyst in the formation of macrocyles and compared it to the $1^{\text {st }}$ generation analogue Cat-1A. ${ }^{35}$ Since Cat-1A is inactive toward $\alpha, \beta$-unsaturated carbonyl compounds, treatment of ester 20 with Cat-1A gave only the homodimer 22 in $62 \%$ 50 isolated yield (Scheme 6). The formation of the expected 7 membered ring did not occur either with the NHC-containing catalyst Cat-1C. The higher activity of this complex allowed the formation of the "head-to-tail" dimer, which was further converted into the macrocycle $\mathbf{2 1}$ by RCM. It appears that the 55 catalyst governs the macrocycle formation but also solvent and concentration have an effect. For example, with Cat-1C, at higher concentrations, the trimeric "head-to-tail" ringclosed product can be obtained. A similar example has been reported by Eustache. ${ }^{36}$

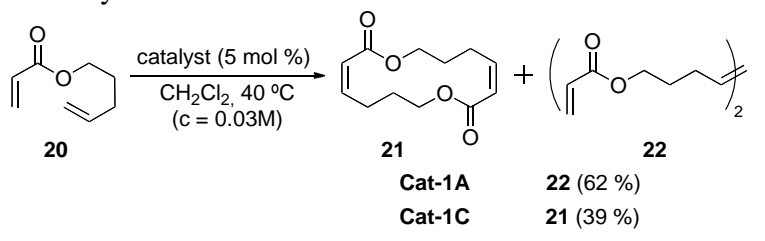

Scheme 6 Formation of macrocycle via dimerisation and RCM

\section{3. $E / Z$ Ratio in Macrocyclisation}

Macrocycles are particularly common in antitumoral, antibiotic and antifungal compounds. Traditional strategies for 65 their synthesis allowing for structure confirmation and pharmacomodulation involve intramolecular macrolactonisations, macrolactamisations or macroaldolisations. Alternatively, some approaches have employed RCM as a key step. ${ }^{1 \mathrm{~d}}$ As illustrated in Scheme 7, 70 Fürstner and co-workers carried out the synthesis of Herbarumin I using a macro RCM as a key step. ${ }^{37}$ The RCM of substrate $\mathbf{2 3}$ was achieved using benzylidene catalyst Cat1B and the ruthenium-indenylidene Cat-2A. A catalytic amount of Cat-2A in refluxing DCM afforded the desired $(E)$ 75 lactone $\mathbf{2 4}$ as the major product, only $9 \%$ of the $(Z)$-isomer was detected. The $E: Z$ ratio being constant during the course of the reaction indicating that the formation of the thermodynamically less stable $(E)$-isomer results from kinetic control. On the other hand, the treatment of diene 23 with 80 catalyst Cat-1B, bearing a NHC, leads to the selective formation of the $Z$ isomer in excellent yield. In order to explain such a difference, the authors suggested that the $\left(\mathrm{PCy}_{3}\right)_{2}$-containing catalysts afforded mainly the $(E)$-isomer 
macrocycle, resulting from a kinetic control. However, the reversibility of the reaction and the superior activity of complexes bearing $\mathrm{NHC}$ led to the formation of the thermodynamically stable $(Z)$-macrocycle with the $2^{\text {nd }}$ 5 generation catalyst. To reach the end-game in this total synthesis, cleavage of acetal groups was performed by treatment with diluted aqueous $\mathrm{HCl}$ providing Herbarumin I (E)-25.
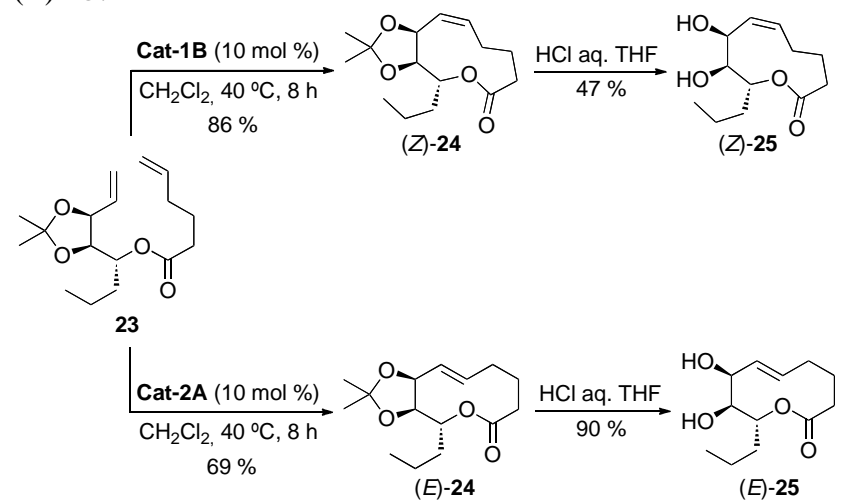

$(E)-25$

10

Scheme 7 Metathesis key-step for the synthesis of Herbarumin I 25

For the synthesis of the 12-membered Salicylihalamide A, a macrocyclisation strategy has been employed using Cat-1A and Cat-1C. ${ }^{38}$ In this case, the selectivity was significantly poorer, since both isomers were obtained with a $E / Z$ ratio of ${ }_{15} \approx 9: 1$ for $1^{\text {st }}$ generation catalyst and $\approx 2: 1$ for $2^{\text {nd }}$ generation.

Recently, Matsuya and Nemoto investigated the formation of 12-membered Salicyclic macrolides via macro-RCM mediated by complexes Cat-1A, Cat-1C, and Cat-3C. ${ }^{39}$ Unprotected diene 26 and protected-phenol such as the tert20 butyldimetylsilyl ether $\mathbf{2 7}$ were used as substrates; results are summarized in Table 2. On both dienes, Cat-1A promoted the formation of the $E$ isomer exclusively, respectively $(E)-\mathbf{2 8}$ and (E)-29. In contrast, when using $2^{\text {nd }}$ generation catalysts Cat$1 \mathrm{C}$ and Cat-3C, both enantiomers were obtained with $E / Z$ 25 ratio $\approx 1: 1$ for product $\mathbf{2 8}$ and $\approx 5: 1$ for $\mathbf{2 9}$, respectively. The authors also investigated the origin of the controlled RCM and suggested a slightly different explanation. Indeed, ${ }^{1} \mathrm{H}$ NMR spectroscopy studies revealed that the $E / Z$ ratio was constant all along the course of the reaction with all catalysts used. 30 More importantly, the interconversion between the $E$ and $Z$ isomers cannot occur since treatments of isolated isomers $(E)$ 28 and (Z)-28 with catalysts Cat-1A and Cat-1C did not result in any product redistribution. Therefore, it has been proposed that this macro-RCM takes place purely under 35 kinetic control and the relative stabilities of $E$ and $Z$ isomers are not involved. However, the stereochemical results would depend on the stabilities of the ruthenacycle intermediates and the difference of rate-determining steps between $1^{\text {st }}$ and $2^{\text {nd }}$ generation catalysts. The formation of the ruthenacycle would 40 be the rate-determining step for phosphine-containing catalysts whereas for those bearing an NHC, it is likely its cleavage. Moreover, as the trans-ruthenacycle is more stable that its $c i s$-counterpart, $1^{\text {st }}$ generation catalyst give only the more stable intermediate providing the $E$-macrocycle. On the 45 other hand, with $2^{\text {nd }}$ generation complex both intermediates are in an equilibrium that is displaced as a function of relative facility of ruthenacycle cleavage leading to the $E / Z$ ratio.

Table 2 Products and yields of RCM for the synthesis of 12-membered Salicylic macrolides

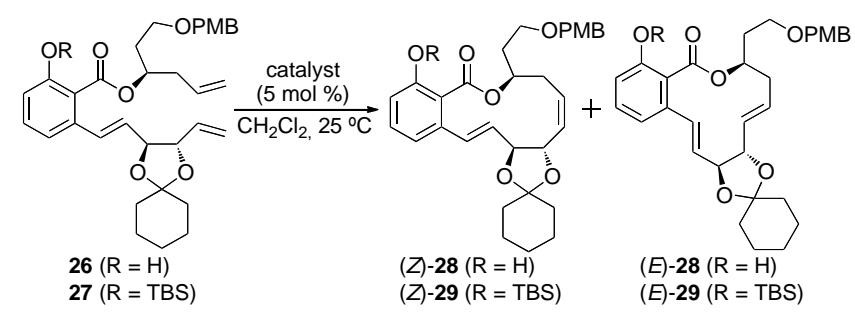

\begin{tabular}{ccccc}
\hline Entry & Substrate & Catalyst & Yield of $(Z)(\%)$ & Yield of $(E)(\%)$ \\
\hline 1 & $\mathbf{2 6}$ & Cat-1A & 0 & 64 \\
2 & $\mathbf{2 6}$ & Cat-1C & 16 & 21 \\
3 & $\mathbf{2 6}$ & Cat-3C & 11 & 10 \\
4 & $\mathbf{2 7}$ & Cat-1A & 0 & 47 \\
5 & $\mathbf{2 7}$ & Cat-1C & 6 & 35 \\
6 & $\mathbf{2 7}$ & Cat-3C & 6 & 30 \\
\hline
\end{tabular}

\subsection{The effect of the alkylidene moiety}

Recently, Fürstner reported the synthesis of 11-membered biaryl lactones of the aspercyclide family. ${ }^{40}$ One of the approaches leading to the structural core made use of a 55 metathesis step. Nonetheless, the ring-closure was found difficult and stoichiometric amounts of ruthenium catalysts were required. Cat-1B and Cat-3C afforded $\mathbf{3 2}$ as major product by cross metathesis between the less hindered alkene in 30 with the benzylidene unit of the ruthenium complex 60 while leading to only small quantities of the cyclised compound 31 (Scheme 8 ). In order to avoid this alkylidene transfer, indenylidene-based catalyst Cat-2A was used leading exclusively to the formation of $\mathbf{3 1}$ in moderate yield. Compared to the benzylidene, the indenylidene with a $\alpha, \alpha$ 65 disubstitution is sterically more hindered which disallows the cross metathesis process. Of note, it would have been interesting to test $2^{\text {nd }}$ generation indenylidene catalysts that have been proven to be more tolerant of harsher reaction conditions. $^{15 \mathrm{~b}}$

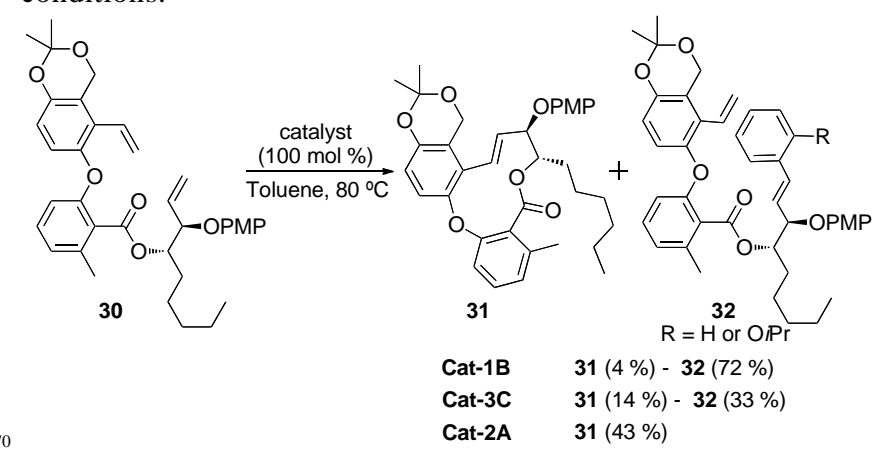

Scheme 8 Synthesis of aspercyclides by metathesis

\section{Ring-Closing Metathesis of Enynes}

Enyne metathesis involves the bond reorganization of an alkyne and an alkene to afford a 1,3-diene. ${ }^{4}$ Enyne metathesis 75 is an atom-economical process driven by the formation of thermodynamically stable conjugated diene that has demonstrated its utility in the context of biologically relevant 
compounds. However the main problem associated with this transformation is the possible formation of endo and exo products. ${ }^{41}$ Exo products are generally exclusively obtained, nevertheless in some cases endo analogues are formed. Mori 5 et al. were the first to report the formation of endo-cyclized rings. ${ }^{42}$ Whereas no reaction occurred using $1^{\text {st }}$ generation catalyst Cat-1A on the hindered enyne 33, both 5- and 6membered rings $\mathbf{3 4}$ and $\mathbf{3 5}$ were isolated in approximately similar amounts with $2^{\text {nd }}$ generation complex Cat-1C (Scheme 10 9). Mori observed that endo product formation takes place uniquely when the $\mathrm{C}-\mathrm{C}$ double bond is sterically hindered. Mechanistically, $\mathrm{Ru}$-alkenylidene active species react on the more reactive $\mathrm{C}-\mathrm{C}$ double bond affording exo products through $\alpha, \beta$-metallacyclobutene $\mathbf{I V},{ }^{43}$ however when it is not 15 possible due the steric hindrance, approach of the alkyne can be cis or trans leading to respectively $\alpha-$ and $\beta$ metallacyclobutene yielding to endo and exo isomers (Scheme 10). ${ }^{41}$ Moreover Mori noticed small amounts of cyclopropanecontaining compounds resulting from a reductive elimination 20 of the ruthenacyclobutane intermediates.

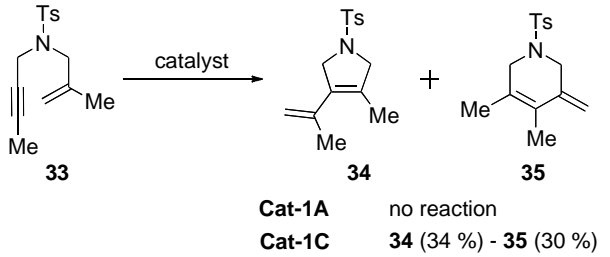

Scheme 9 Ring-closing metathesis of enyne

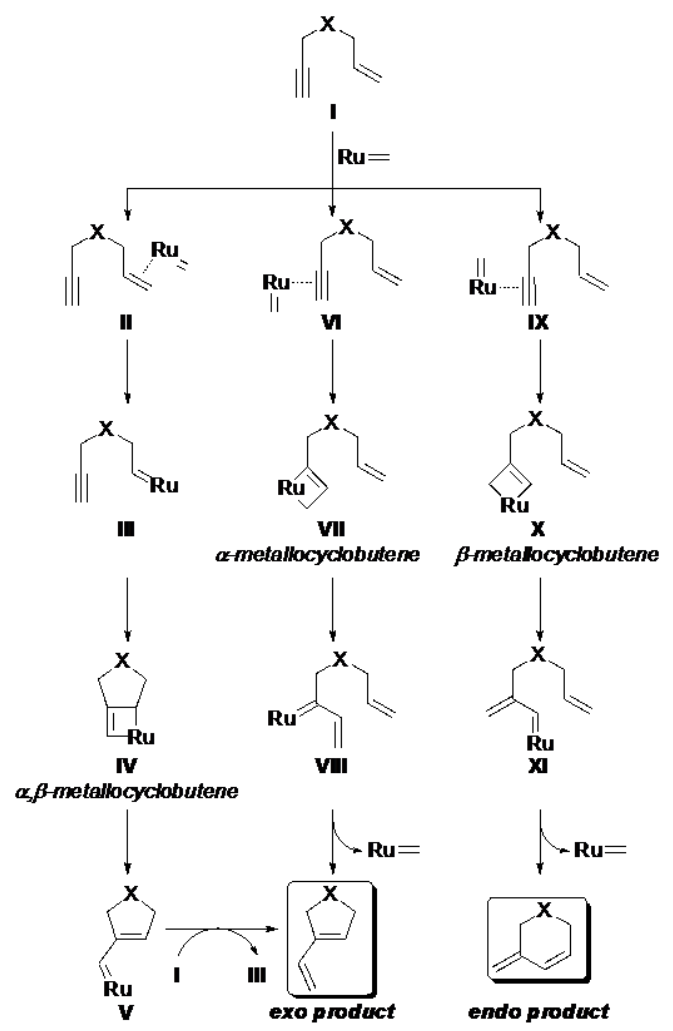

Scheme 10 Reaction pathways in Ring-closing metathesis of enyne

${ }_{25}$ In the course of a study involving a latter generation catalyst, Grela observed the formation of unexpected products in enyne
RCM as a function of the Ru-complex used. ${ }^{44}$ As a consequence, the pioneering work of Mori was further elaborated in order to examine the influence of the catalyst. ${ }^{45}$ 30 It was already reported that RCM of enyne $\mathbf{3 6}$ mediated by $1^{\text {st }}$ generation catalyst Cat-1A gave only the 5-membered ring 37, ${ }^{42}$ this was also the case with $1^{\text {st }}$ generation Hoveyda and Grela catalysts, respectively Cat-3A and Cat-4A (entries 1 and 2, Table 3 ). On the other hand, using their congeners 35 bearing a NHC ligand, small but significant amounts of endo cyclized product 38 were isolated, particularly with Cat-4C (entries 3-5). Of note, minor quantities of cyclopropane derivative 39 were equally detected when $2^{\text {nd }}$ generation catalysts were employed.

Table 3 Products distribution for RCM of enyne $\mathbf{3 6}$

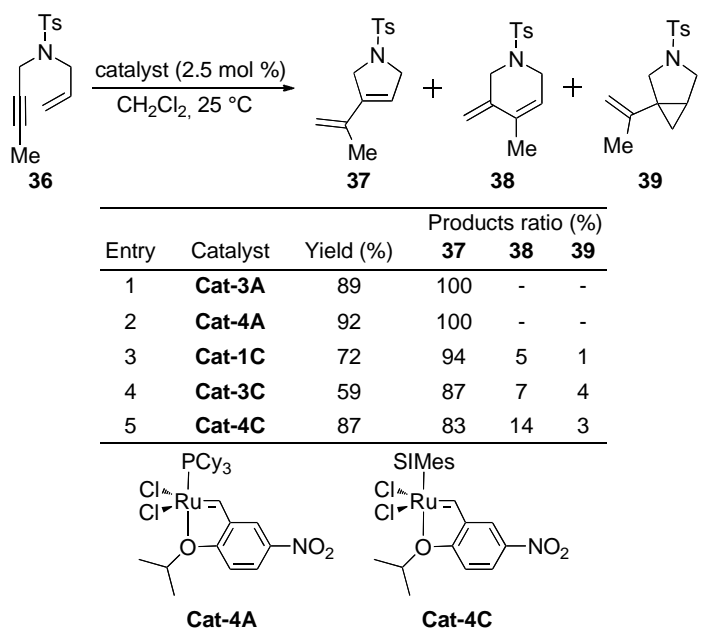

A similar example has been described for the synthesis of carbohydrate derivatives using an enyne RCM methodology. ${ }^{46}$ As depicted in Scheme 11, treatment of enyne $\mathbf{4 0}$ with $1^{\text {st }}$ 45 generation catalyst Cat-1A afforded the 5-membered diene $\mathbf{4 1}$ in moderate yield with traces of its dimer 43. When Cat-1C was employed in the same reaction, $\mathbf{4 1}$ was still the major product with also traces of $\mathbf{4 3}$, but $25 \%$ of 6 -membered ring endo product $\mathbf{4 2}$ was also isolated. In this case, the C-C 50 double is not directly hindered, but the benzyloxy function in the allyl position should contribute to its lower reactivity.

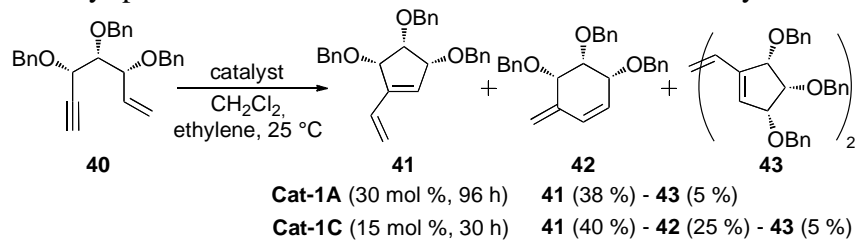

Scheme 11 Carbohydrate derivatives synthesis by enyne RCM

Of note, these issues of chemoselectivity have also been 55 pointed out with molybdenum-type catalysts. Recently, Hoveyda reported the synthesis of a new molybdenum-based catalyst Cat-Mo that gave selectively the endo cyclised product even when no steric congestion is present on the alkene moiety. ${ }^{47}$ More interestingly, in the case of competition 60 between thermodynamically favored 6- and unfavoured 7membred rings, the 7-membered ring endo isomer was exclusively obtained. 


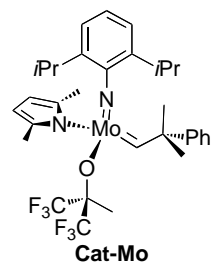

To confirm results obtained with enyne 36, Grela and Sashuk studied the cascade enyne RCM of linear dienyne (Table 4). ${ }^{45}$ With complexes Cat-3A and Cat-4A, the dihydrofuran 5 derivative 46 was isolated as the main product together with small amounts of bisdihydrofuran 45 (entries 1 and 2). The presence of a methyl group on one of the alkenes hindered the second RCM with less active phosphine-containing catalysts. This did not occur with Cat-3C and Cat-4C, since no 10 dihydrofuran 46 was obtained; but quantities of bicyclic compound $\mathbf{4 5}$ were still low (entries 3 and 4). The 6membered heterocycle $\mathbf{4 7}$, issue from endo cyclisation, was also observed in low yields. According to results presented in tables 3 and 4, the nitro-activated version of Hoveyda-Grubbs 15 catalyst Cat-4C shows a better performance in the formation of endo cyclised products.

Table 4 Cascade enyne RCM of dienyne 44

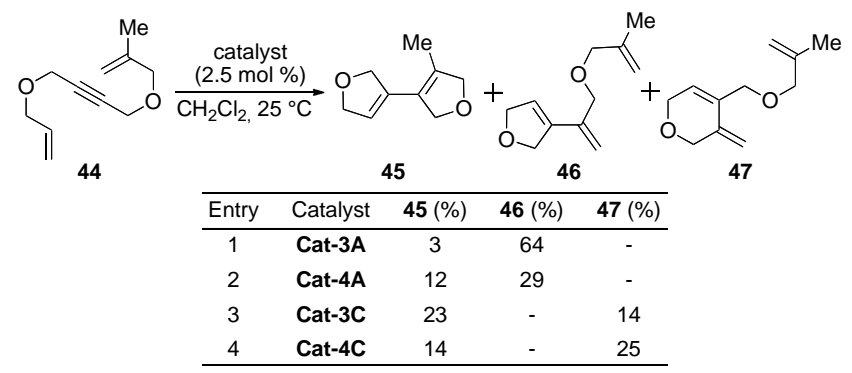

During the investigation of the reaction scope of $\mathrm{Ru}$ 20 indenylidene complexes, ${ }^{15 b}$ Clavier and Nolan observed also the formation of endo products, which were investigated as a function of the $\mathrm{L}$ ligand borne on the active catalytic species. ${ }^{48}$ Dienyne $\mathbf{4 8}$ was selected as the model substrate (Table 5). The $1^{\text {st }}$ generation indenylidene catalyst Cat-2A ${ }_{25}$ gave cleanly the bisheterocycle 49 (entry 1). With IMescontaining complex Cat-2B, 49 was found to be the only product formed, but when the reaction conversion was improved, a small amount of dihydropyrrole 50 was observed as was the case for Cat-2D bearing the more sterically 30 demanding IPr (entries 2 and 4). Using a different NHC: SIMes in Cat-2C, the by-product was found to be hexahydro2,6-naphthyridine 51. Unexpectedly, a minute variation of the NHC ligand, as in the saturation of its backbone, allowed for the formation of an endo 6-membered ring. Of note, another 35 product was obtained with a phosphabicyclononanecontaining indenylidene complex but could not be identified. ${ }^{49}$

Table 5 RCM of tosylamine-containing dienyne 48

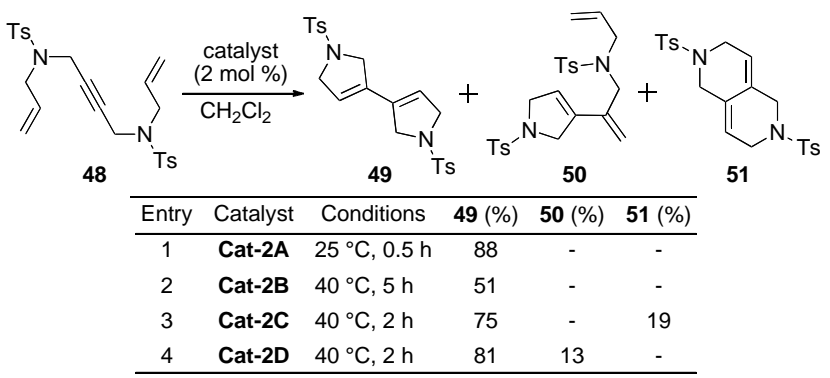

${ }_{45}$ When the more hindered dienyne $\mathbf{5 2}$ was employed in order to obtain single-crystal for X-ray analysis allowing for structure confirmation of products 53-56, Cat-2A was found inefficient (Table 6, entry 1). Cat-2B and Cat-2D led to the formation products $\mathbf{5 3}$ and $\mathbf{5 4}$ with a 5-membered ring core (entries 2 50 and 4). In sharp contrast, catalyst Cat-2C gave compounds 55 and 56 issue from endo cyclization (entry 3). Through experimental and DFT calculations, information on the mechanism supports the co-existence of ene-then-yne and yne-then-ene reaction pathways. The $1^{\text {st }}$ generation catalysts 55 react according to the ene-then-yne pathway giving rise to exclusively exo cyclized products. Complexes bearing an NHC can follow both pathways as a function of the steric hindrance of C-C double and triple bonds. When the alkene is accessible and the alkyne congested, the ene-then-yne ${ }_{60}$ pathway is dominant. In the opposite case, the yne-then-ene pathway seems to prevail but all products can be formed. DFT calculations showed that for $\mathrm{NHC}=$ SIMes, the endo cyclization is favorable, whereas for IPr exo cyclizations is slightly privileged. In all the previous examples, the formation 65 of endo occurs only when SIMes-complexes are employed, this seems to be a general trend.

Table 6 Cascade dienyne RCM of $\mathbf{5 2}$

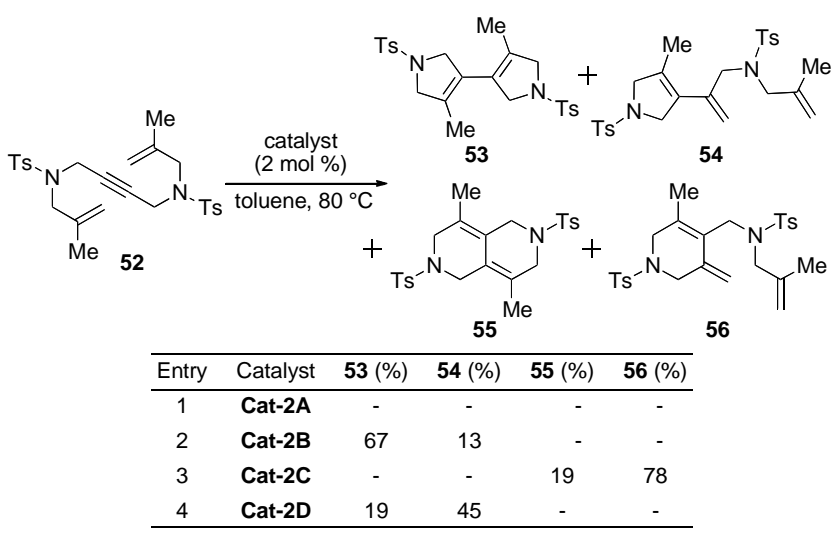

The reactivity of other types of dienynes has also been 70 investigated. For example, Hanna et al. were interested in the construction of polyoxygenated bicyclic moieties through dienyne RCM. ${ }^{50}$ While the more active $2^{\text {nd }}$ generation catalyst Cat-1C was able to complete the metathesis sequence affording the bicyclic compound $\mathbf{5 9}$ in quantitative yield, 75 treatment of dienyne $\mathbf{5 7}$ with Cat-1A under these reaction conditions gave rise to the monocyclic product $\mathbf{5 8}$ (Scheme 12). This is a representative example of the difference in RCM 
activity of complexes Cat-1A and Cat-1C.

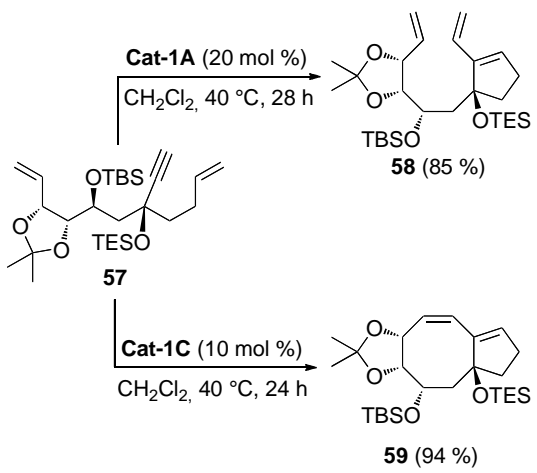

Scheme 12 Construction of polyoxygenated bicyclic compounds via dienyne metathesis

${ }_{5}$ Lui and co-workers have also investigated the dienyne ringclosing metathesis as a methodology leading to the formation of oxygen-containing bicyclic systems. ${ }^{51}$ Among the substrates examined, dienyne $\mathbf{6 0}$ is of interest since numerous products are formed as a function of the catalyst used 10 (Scheme 13). Both complexes Cat-1A and Cat-1C displayed a good activity leading to the formation of dioxabicyclo[4.4.0]decane $\mathbf{6 1}$ as major product, resulting from an endo cyclization. Nonetheless, 5-membered ring-based compounds were obtained as byproducts. $\mathbf{6 3}$ was isolated with 15 the less competent Cat-1A, while Cat-1C was efficient in performing the second RCM affording dioxabicyclo[5.3.0]decane 62 .

Me

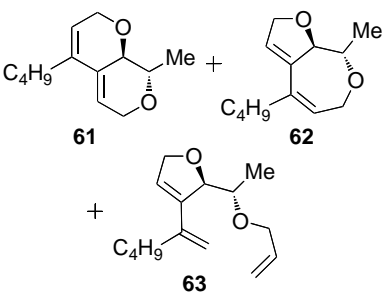

Cat-1A

Cat-1C

$61(62 \%)$ - 62 (traces) - 63 ( $23 \%)$ $61(64 \%)-62(21 \%)-63$ (traces)
Scheme 13 Dienyne RCM for the synthesis of oxygen-containing bicyclic
products

For the total synthesis of (+)- $\beta$-Erythroidine, a strategy involving a RCM step of ene-yne was put into action. ${ }^{52}$ During the course of this study, an intriguing example of chemoselectivity was illustrated (Scheme 14). As a function 25 of the catalyst employed and/or the configuration of the chiral centre in position 12 of the substrate $\mathbf{6 4}$, the outcome of the dienyne RCM was completely different. Treatment of $(S)-64$ with Cat-1A gave only bicyclic compound $\mathbf{6 5}$ coming from the RCM with the C-C double bonds and no involvement of 30 the alkyne. On the other hand, Cat-1C catalyzed the metathesis of $(R)$-64 with participation of all unsaturated bonds affording the tricycle $\mathbf{6 6}$ in good yield with no traces of 65. Unfortunately, no crossover experiments have been reported so far to determine if the complex used or the $12 \mathrm{C}$ 35 configuration was responsible for such dissimilarity in reactivity. The configuration of carbon 12 seems to be far

enough to not influence dienyne RCM transformation, but it cannot be unequivocally discounted.

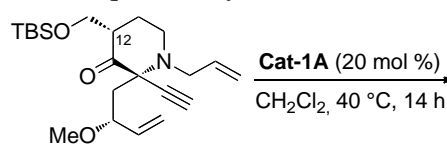

(S)-64

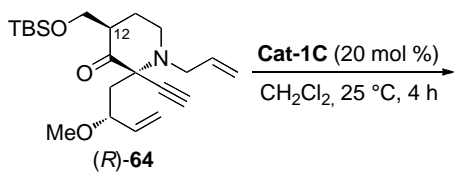

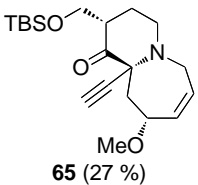

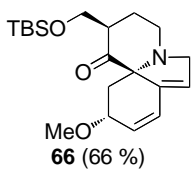

40 Scheme 14 Synthesis of (+)- $\beta$-Erythroidine analogues via enyne RCM

A similar example described the construction of taxosteroids by dieyne RCM methodology. ${ }^{53}$ Recently Movassaghi noticed some differences in product distribution of a dienyne RCM key step in the synthesis of an antitumor Illudins core. ${ }^{54}$

${ }_{45}$ Olefin metathesis was also investigated to accomplish simultaneous or sequential processes known as tandem reactions. ${ }^{55}$ In this context, Snapper et al. reported the tandem enyne metathesis - cyclopropanation sequences. ${ }^{56}$ Successfully, in the presence of the bisphosphine catalyst ${ }_{50}$ Cat-1A, alkenyl cyclopropane 68 was obtained from enyne 67 and diazoester (Scheme 15). Cyclopropanation took place mostly exclusively at the less hindered double bond. Attempts to use the SIMes-Ru complex Cat-1C, in the same process failed; in this case the superior activity of the catalyst led to a 55 second cross metathesis step after the enyne metathesis yielding to triene 69. Of note, this is one of the rare examples of additional cross metathesis in enyne metathesis.

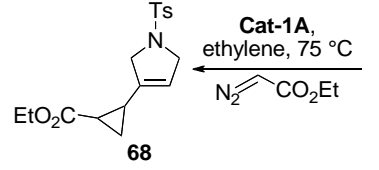

Scheme 15 Tandem enyne metathesis - cyclopropanation

${ }_{60}$ During the course of a study aiming to synthesise functionalized fused oxazepine frameworks via a enyne RCM step, the formation of an expected product was observed. ${ }^{57} \mathrm{As}$ depicted in Scheme 16, the treatment of enyne 70 with NHCcontaining ruthenium catalyst Cat-1C gave rise to 65 dihydropyridine 72, resulting from elimination of propargyl alcohol as the unique product. Surprisingly, in spite of much reaction conditions optimisation, Cat-1C was not able to promote the ring-closure. Alternatively, under the same reaction conditions, first-generation complex Cat-1A reacted 70 with $\mathbf{7 0}$ to yield the desired pyrido[2,1-b]- [1,3]oxazepine $\mathbf{7 1}$. Variation of reaction conditions affected the $\mathbf{7 1 / 7 2}$ ratio and the RCM carried out at room temperature and under ethylene atmosphere using $10 \mathrm{~mol} \%$ of Cat-1A led to the formation of $\mathbf{7 1}$ as single product (90\% yield). 
i0

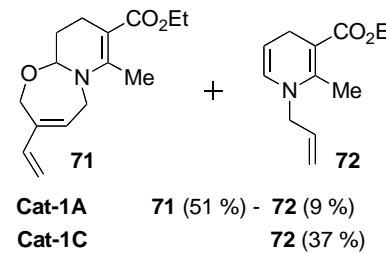

Scheme 16 Synthesis of fused oxazepine analogues by enyne RCM

\section{Ring-Rearrangement Metathesis}

Ring-Rearrangement metathesis is defined as a combination 5 of metathesis reactions carried out in one pot - domino reactions - which involve generally ring-opening metathesis (ROM), RCM and/or cross metathesis. ${ }^{6}$ Combinations of several metathesis steps involving $\mathrm{C}-\mathrm{C}$ double or triple bonds allow for the straightforward construction of complex 10 scaffolds.

\subsection{Ring-rearrangement metathesis involving C-C double bonds}

One of the most interesting chemoselective RRM was described in 2004 by Holtsclaw and Koreeda and deals with 15 the synthesis of cyclopenta- and cyclohexa[c]indenes. ${ }^{58}$ As depicted in Scheme 17, treatment of the homoallyl-tethered enone $\mathbf{7 3}$ with $\left(\mathrm{PCy}_{3}\right)_{2}$-containing catalyst Cat-1A gave smoothly and quantitatively the tricyclic enone $\mathbf{7 4}$. When the same reaction was conducted with $2^{\text {nd }}$ generation catalysts

${ }_{20}$ Cat-1C and Cat-3C, a significant amount of spirocycloheptenone $\mathbf{7 5}$ was obtained (ca. $20 \%$ ). Interestingly, whereas the conversion of $\mathbf{7 4}$ into $\mathbf{7 5}$ was found to be impossible, reaction of $\mathbf{7 5}$ with Cat-1C gave cleanly the cyclohexa[c]indene system $\mathbf{7 4}$ and showed the higher 25 thermodynamic stability of $\mathbf{7 4}$. This raises the question of why usually superior performing complexes, (bearing a NHC ligand) were not able to reach reaction completion where Grubbs I Cat-1A could. Surprisingly, the same metathesis transformation performed on 76, the methylated counterpart of $30 \mathbf{7 3}$, led to the formation of tricyclic enone $\mathbf{7 4}$ with Cat-1A, but with Cat-1C the spiro compound $\mathbf{7 5}$ was now the major product (Scheme 18). RRM of allyl-tethered enone leading to cyclopenta[c]indene derivatives also exhibited some chemoselectivity but parameters governing this reactivity 35 remain unclear.

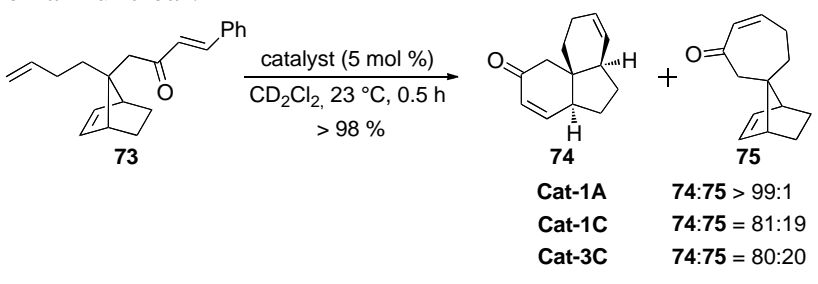

Scheme 17 RRM of norbornene derivative

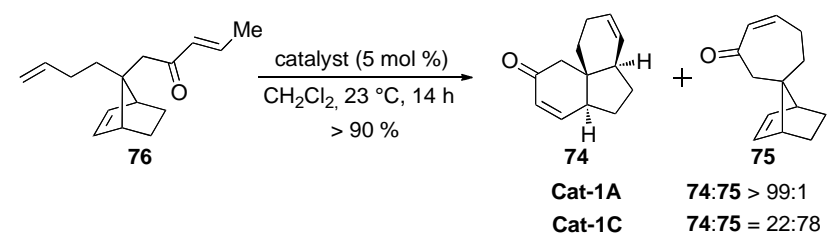

Scheme 18 RRM of norbornene derivative
40 When treated with $1^{\text {st }}$ or $2^{\text {nd }}$ generation Grubbs catalysts, cyclopentene $\mathbf{7 7}$ afforded $\mathbf{7 8}$ and $\mathbf{7 9}$ with very differents ratios (Scheme 19). ${ }^{59}$ The authors suggested that the RRM leading to the fused bicyclic product $\mathbf{7 8}$ takes place under thermodynamic control whereas $\mathbf{7 9}$ results from the simple ${ }_{45} \mathrm{RCM}$ reaction affording the kinetically controlled product $\mathbf{7 9}$.

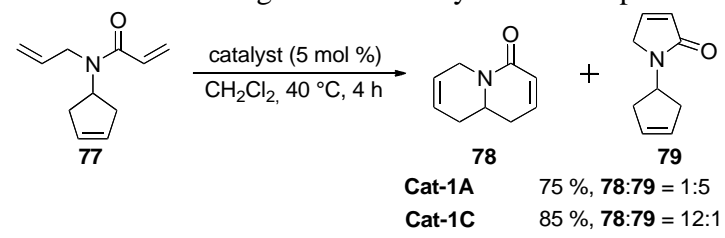

Scheme 19 RRM of cyclopentene derivative

Metathesis reaction of the $N, N^{\prime}$-diallyl- $N, N^{\prime}$-bis-tosyl cisdiamine $\mathbf{8 0}$ in the presence of catalyst Cat-1A bearing 50 tricyclohexylphosphine formed exclusively the 6,8-fused bicycle $\mathbf{8 1}$ by simple RCM reaction (Scheme 20). ${ }^{60}$ The same reaction carried out under ethylene atmosphere also gave $\mathbf{8 1}$ as the single product. Alternatively, when $2^{\text {nd }}$ generation catalyst Cat-1C was employed, a second product was formed 55 in significant amounts and was identified as the bisdihydropyrrolidine $\mathbf{8 2}$. Compound $\mathbf{8 2}$ results formally from a ring-opening metathesis followed by RCM. Under ethylene atmosphere, the reaction proceeded much more slowly but the $\mathbf{8 1 / 8 2}$ ratio was found to be the same. Regrettably, the 60 transformation of $\mathbf{8 1}$ into bis-dihydropyrrolidine $\mathbf{8 2}$ was not attempted. This would had provided mechanistic information as to whether RCM yielding $\mathbf{8 1}$ and ROM leading to $\mathbf{8 2}$ were competing or if the higher activity of $2^{\text {nd }}$ generation catalysts allows for the formation of the presumably more stable 65 compound $\mathbf{8 2}$ from $\mathbf{8 1}$. In the last case, the RRM mechanism would be different than the expected tandem ROM/RCM.

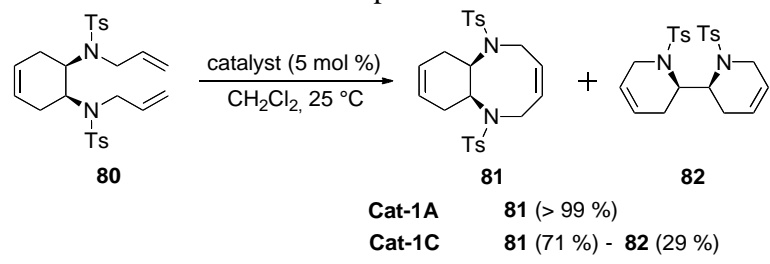

Scheme 20 RRM of cyclohexene derivative

4.2. Ring-rearrangement metathesis involving C-C triple 70 bonds

Metathesis transformations involving a $\mathrm{C}-\mathrm{C}$ triple bond are generally conducted under ethylene atmosphere, due to a improved stability of the active species in the presence of ethylene gas. ${ }^{61}$ However, ethylene can also be a reagent and as 75 shown in Scheme 21 react with C-C triple bonds. ${ }^{62}$ When cyclohexen-yne $\mathbf{8 3}$ and catalyst Cat-1A were stirred at room temperature in dichloromethane under an atmosphere of ethylene only 1,3-diene $\mathbf{8 4}$ was isolated as product of ethylene cross enyne metathesis. This example illustrates the lack of 80 activity of $1^{\text {st }}$ generation catalyst toward cyclic C-C double bonds, as previously mentioned (Scheme 21). When $\mathbf{8 3}$ was treated with Cat-1C under the same conditions, 84 was not observed and 3 other products were isolated. The 16membered ring compound $\mathbf{8 7}$ resulting from ${ }_{85} \mathrm{RRM} /$ dimerization process was found to be the major product. 
Its monomer $\mathbf{8 6}$ and $\mathrm{RRM} /$ isomerization/RCM product $\mathbf{8 5}$ were obtained is small quantities.

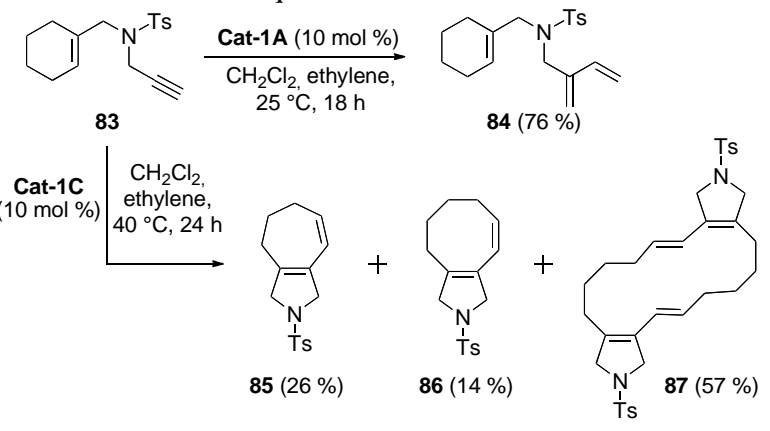

Scheme 21 ROM-RCM sequence of cyclohexen-yne

${ }_{5}$ Having established that treatment of norbornene derivative $\mathbf{8 8}$ by Cat-1C yielded a complex mixture of products, Spring tested the less reactive $1^{\text {st }}$ generation complex Cat-1A (Scheme 22). ${ }^{63}$ This catalyst permitted the formation of the ring-opened compound $\mathbf{8 9}$, in a reaction with ethylene, in 10 moderate isolated yield but with only traces of by-products only 90 was observed. Then a second step, a metathesis mediated by $2^{\text {nd }}$ generation catalyst Cat-1C afforded the bicycle compounds 91 with again 90 as by-product but in small amounts. This strategy exploits the activity difference 15 between both catalyst generations in order to minimize formation of unwanted by-products; nevertheless the development of task specific catalysts would be beneficial for sustainable chemistry. Of note is a related example of diversity-oriented synthesis in metathesis that was reported by 20 North and co-workers. ${ }^{64}$

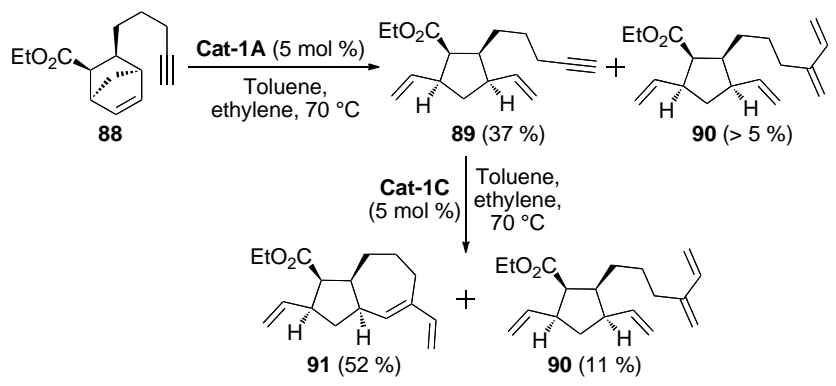

Scheme 22 ROM-RCM sequence of cyclohexen-yne

\section{Cross Metathesis}

Despite a clearly important potential, the intermolecular 25 variant of metathesis, namely cross metathesis, was neglected in the 90's. However, with the development of new ruthenium-based complexes exhibiting improved efficiency and tolerance to functional groups, the interest in this transformation has tremendously increased. Perfect reaction 30 selectivity using this methodology, such as the control of the $E / Z$ selectivity, remains a goal yet unreached. ${ }^{5}$ For instance, the self metathesis of oleochemicals is of considerable interest for the conversion of low value feedstock into useful chemicals in petrochemistry and polymerization. ${ }^{65}$

35 Recently, Stockman and co-workers investigated the simultaneous elongation of a symmetrical substrate in two directions by cross-metathesis. ${ }^{66}$ For example, CM between diene 92 and 6 equivalents of ethyl acrylate was performed using Cat-1B and Cat-3B ${ }^{67}$ (Scheme 23). Whereas Hoveyda40 type catalyst Cat-3B displayed good activity and gave in excellent yield the dihomologated product 94, Cat-1B failed reach completion and mono $\mathrm{CM}$ product $\mathbf{9 3}$ was obtained as the major product. Considering the long reaction time required for this reaction, the superior stability of Cat-3B is a 45 significant advantage.

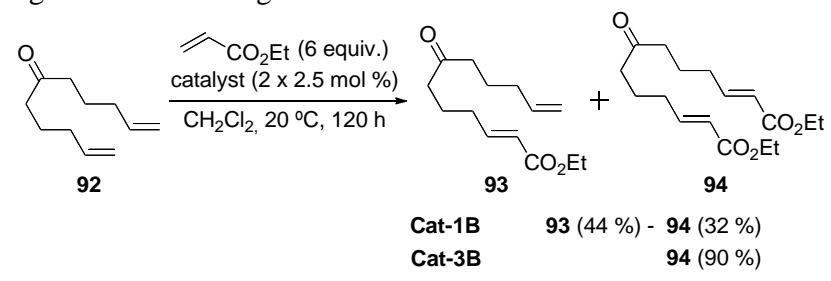

Scheme 23 Two-directional cross metathesis

In spite of the relevance of the $E / Z$ control in $C M$, newly synthesized catalysts are not systematically tested and only a ${ }_{50}$ few reports present a thorough comparison of $E / Z$ ratio as a function of the catalyst used. Nevertheless, it has been shown that the active sites in metathesis could be characterized through the reaction stereoselectivity at low conversion. ${ }^{68}$ In 2009, Thieuleux reported, using several complexes, the self55 metathesis of ethyl oleate 95 affording 9-octadecene 96 and diethyl 1,18-octadec-9-enedioate 97, which may be valuable for materials applications (Table 7). ${ }^{69}$ Conversions only reach $50 \%$ due to the presence of a thermodynamic equilibrium; the reversible reaction or unproductive metathesis leads to the 60 formation of the $E$-isomer of the ethyl oleate, i.e. ethyl aleidate. Therefore, $E / Z$ ratio must be determined at an early stage of the transformation and then can be extrapolated for the equilibrium as presented in the Table 7. Results showed a clear difference between $1^{\text {st }}$ - (Cat-1A, Cat-2A, and Cat-3A) 65 and $2^{\text {nd }}$-generation catalysts (Cat-1B, Cat-1C, and Cat-3C) with respective $E / Z$ ratios $\approx 3.5: 1$ and $2.5: 1$ for both products 96 and 97. It seems that the saturation or unsaturation of NHC backbone does not play a role in the selectivity (entries 4 and 5). These results are in line of those for macrocyclisation, 70 which, in a way, can be linked to cross metathesis. The better performance of NHC-containing catalysts allows for olefin approach to the ruthenium-alkylidene in syn or anti manner and consequently displays a lower $E / Z$ stereoselectivity.

Table 7 E/Z selectivity in cross metathesis of ethyl oleate

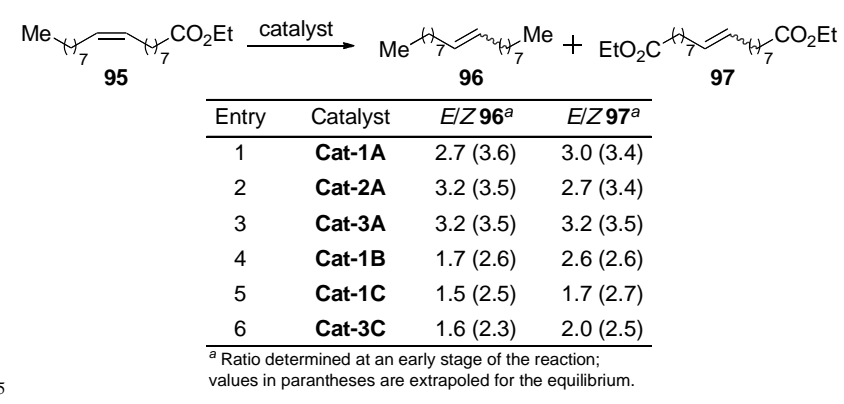

Another representative example was reported by Grubbs. ${ }^{70}$ The CM reaction between allylbenzene $\mathbf{9 8}$ and $\mathbf{9 9}$ afforded the $\mathrm{CM}$ product $\mathbf{1 0 0}$ in good yield but a moderate to good stereoselectivity as a function of the catalyst used (Scheme 
24). With Cat-1C, the selectivity is largely in favor of the thermodynamically more stable trans isomer due to the higher activity of this complex which facilitates the cis/trans isomerization by a secondary metathesis process.
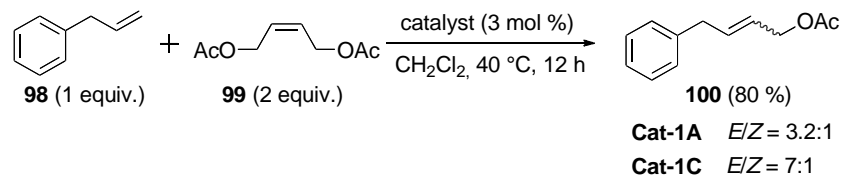

Scheme 24 Representative example of $E / Z$ selectivity in CM

Cross metathesis involving acrylonitrile as reaction partner is one of the rare examples leading to mostly the $Z$ isomer. Grubbs and co-workers evaluated several ruthenium10 complexes in the reaction of acrylonitrile with allylbenzene 98. ${ }^{71}$ Tests were performed in dichloromethane at $40{ }^{\circ} \mathrm{C}$ for 12 h using $2.5 \mathrm{~mol} \%$ of catalyst; yields and selectivities were found to vary as a function of the complex used (Table 6). Whereas Grubbs II Cat-1C gave 101 in poor yield with $E / Z$ 15 ratio $=1: 1.7$ (entry 1), its Hoveyda analogue Cat-3C and its 3-bromopyridine counterpart Cat-5C were found much more efficient but of equivalent stereoselectivity (entries 2 and 5). The $2^{\text {nd }}$ generation catalyst bearing triphenylphenyl phosphine Cat-5A showed a better $E / Z$ ratio $=1: 4$ (entry 3 ) and, in 20 contrast, substitution of phosphine ligand by two pyridines Cat-5B gave a $E / Z$ selectivity close to $1: 1$ (entry 4 ). These examples support the unexpected non-innocent role of released ancillary ligands on metathesis selectivity.

Table 8 Yields and $E / Z$ ratios for CM between allylbenzene and

25 acrylonitrile

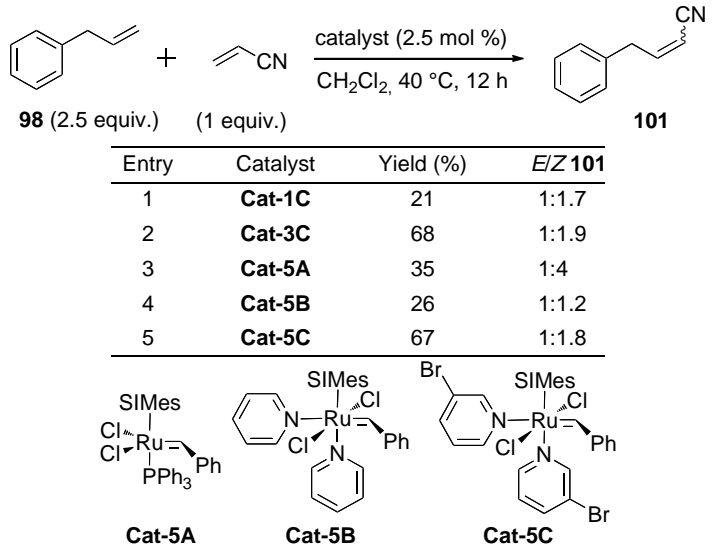

Cross metathesis between alkyne and alkene was also studied using several catalysts. ${ }^{72}$ In the particular case depicted in Table 9, the $E$ isomer $(E) \mathbf{- 1 0 3}$ was easily isolated when $(Z)$ 30103 further reacted to yield 104 by RCM. Thus, the $E / Z$ ratio of the enyne cross metathesis can be determined in a straightforward manner by the $(E)-\mathbf{1 0 3 / 1 0 4}$ ratio. Usually the major product is the thermodynamically more stable $E$ isomer, however the further RCM of the $Z$ isomer favors its formation.

35 The activity of Cat-1A was found very low with a $E / Z$ ratio close to 1 (entry 1), whereas the more competent Cat-1C formed principally the $E$ isomer at room temperature (entry 2); at higher temperature (E)-103 was still the major product but the ratio varied slightly (entry 3 ). The chiral
${ }_{40}$ benzimidazolylidene catalyst Cat-1F was also tested showing lower performance and an $E / Z$ ratio slightly in favor of the $\mathrm{Z}$ isomer (entry 4). Similarly to common cross metathesis presented above, the nature of the catalyst can influence the selectivity of the reaction but differences reported to date are 45 minute.

Table 9 E/Z ratios Enyne cross metathesis

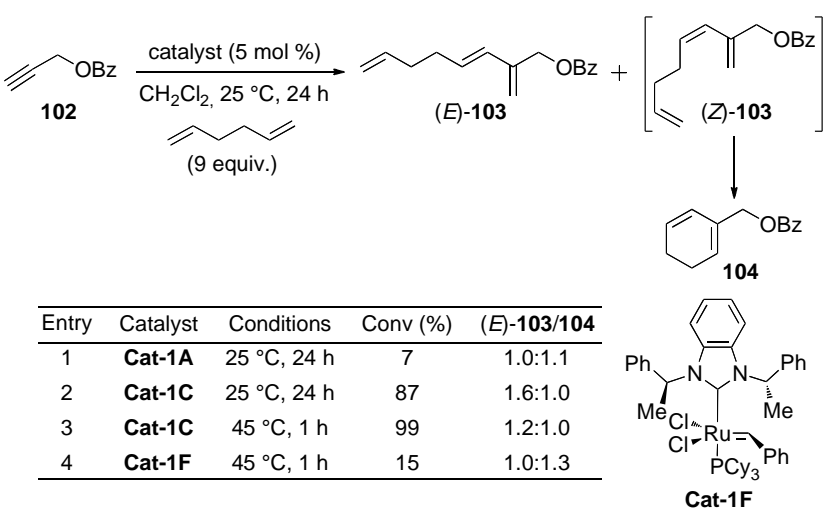

\section{Concluding Remarks}

Two decades after the first reports on ruthenium-mediated 50 olefin metathesis transformations, this powerful reaction still attracts significant attention. Whereas efforts are still focused on the development of catalysts with ever increasing activity, the stereoselectivity questions arising in these uses has only been barely examined. Chemoselectivity issues are sometimes 55 postulated, but only rarely investigated. Nonetheless, differences in complex reactivity leading to the formation structurally different compounds were reported for all metathesis transformations, including diene and enyne RCM, ring-rearrangement and cross metathesis.

${ }_{60}$ Differences in metathesis chemoselectivity were observed mainly between first and second generation ruthenium catalysts as a result of activity difference between both generations showing the crucial role played by the phosphine and the NHC. However it has been reported that the 65 architecture of the ancillary ligand, could also significantly influence the outcome of metathesis transformations. The steric bulk of NHCs was found determinant for the selective formation of expected products. In rare cases, the nature of the alkylidene moiety was found important.

70 Among the number of metathesis examples leading to the formation of different products, the usual trend is to optimize reaction conditions, such as solvent, temperature, ethylene atmosphere or not, etc, in order to favour the formation of the expected product. The influence of the catalyst used has 75 barely been investigated and complexes employed are limited to commercially available catalysts (mainly $1^{\text {st }}$ and $2^{\text {nd }}$ generation Grubbs and Hoveyda catalysts). We believe there is a need for the commercialization of different catalysts as this will facilitate the development of chemoselective 80 metathesis. Thus, the development of task-specific metathesis catalysts, using or not transition metals other than ruthenium, will certainly be of interest to the further development of olefin metathesis. 


\section{Acknowledgements}

This work was supported by the Centre National de la Recherche Scientifique (HC) and by the EC through the seventh framework program through grant CP-FP 211468-2${ }_{5}$ EUMET (SPN). Dr. Julie Broggi is acknowledged for useful comments on the manuscript.

\section{Notes and references}

${ }^{a}$ School of Chemistry, University of St Andrews, St Andrews, KY16 9ST,

United Kingdom E-mail: snolan@st-andrews.ac.uk

$10{ }^{b}$ Université Aix-Marseille, UMR CNRS 6263 - Institut des Sciences

Moléculaires de Marseille, Av. Escadrille Normandie Niemen, 13397

Marseille Cedex 20, France.E-mail: herve.clavier@univ-cezanne.fr

1 For reviews on synthetic applications, see: (a) A. Deiters and S. F.

15 Martin, Chem. Rev., 2004, 104, 2199-2238. (b) M. D. McReynolds, J. M. Dougherty and P. R. Hanson, Chem. Rev., 2004, 104, 2239-2258. (c) K. C. Nicolaou, P. G. Bulger and D. Sarlah, Angew. Chem. Int. Ed., 2005, 44, 4490-4527. (d) A. Gradillas and J. Pérez-Castells, Angew. Chem. Int. Ed., 2006, 45, 6086-6101. (e) A. H. Hoveyda and

20 A. R. Zhugralin, Nature, 2007, 450, 243-251. (f) S. Kotha and K. Lahiri, Synlett, 2007, 2767-2784. (g) W. A. L. van Otterlo and C. B. de Koning, Chem. Rev., 2009, 109, 3743-3782.

2 Y. Schrodi and R. L. Pederson, Aldrichimica Acta, 2007, 40, 45-52.

3 S. K. Chattopadhyay, S. Karmakar, T. Biswas, K. C. Majumdar, H.

25 Rahaman and B. Roy, Tetrahedron, 2007, 63, 3919-3952.

4 (a) S. Diver and A. J. Giessert, Chem. Rev., 2004, 104, 1317-1382. (b) S. T. Diver, J. Mol. Catal. A, 2006, 254, 29-42. (c) S. T. Diver, Coord. Chem. Rev., 2007, 251, 671-701. (d) H. Villar, M. Frings and C. Bolm, Chem. Soc. Rev., 2007, 36, 55-66.

305 S. J. Connon and S. Blechert, Angew. Chem., Int. Ed., 2003, 42, 1900-1923.

6 N. Holub and S. Blechert, Chem. Asian J., 2007, 2, 1064-1082.

7 (a) M. R. Buchmeiser, Chem. Rev., 2000, 100, 1565-1604. (b) C. Slugovc, Macromol. Rapid Commun., 2004, 25, 1283-1297. (c) C. W. Bielawski and R. H. Grubbs, Prog. Polym. Sci., 2007, 32, 1-29.

8 For reviews on Ru-based metathesis catalysts, see: (a) Handbook of Metathesis, ed. R. H. Grubbs, Wiley-VCH, Weinheim, 2003. (b) D. Astruc, New J. Chem., 2005, 29, 42-56. (c) P. H. Deshmukh and S. Blechert, Dalton Trans., 2007, 2479-2491. (d) C. Samojzowicz, M.

40 Bieniek and K. Grela, Chem. Rev., 2009, 109, 3708-3742. (e) G. C. Vougioukalakis and R. H. Grubbs, Chem. Rev., 2010, 110, doi: $10.1021 / \mathrm{cr} 9002424$.

9 (a) P. Schwab, M. B. France, J. W. Ziller and R. H. Grubbs, Angew. Chem. Int. Ed. Engl., 1995, 34, 2039-2041. (b) P. Schwab, R. H.

45 Grubbs and J. W. Ziller, J. Am. Chem. Soc., 1996, 118, 100-110.

10 (a) J. Huang, H. J. Schanz, E. D. Stevens and S. P. Nolan, Organometallics, 1999, 18, 2370-2375. (b) A. Fürstner, O. R. Thiel, L. Ackermann, H. J. Schanz and S. P. Nolan, J. Org. Chem., 2000, 65, 2204-2207. (c) A. Fürstner, O. Guth, A. Düffels, G. Seidel, M.

50 Liebl, B. Gabor and R. Mynott, Chem. Eur. J., 2001, 7, 4811-4820.

11 J. S. Kingsbury, J. P. A. Harrity, P. J. Bonitatebus and A. H. Hoveyda, J. Am. Chem. Soc., 1999, 121, 791-799.

12 (a) J. Huang, E. D. Stevens, S. P. Nolan and J. L. Petersen, J. Am Chem. Soc., 1999, 121, 2674-2678. (b) M. Scholl, T. M. Trnka, J. P. Morgan and R. H. Grubbs, Tetrahedron Lett., 1999, 40, 2247-2250.

13 M. Scholl, S. Ding, C. W. Lee and R. H. Grubbs, Org. Lett., 1999, 1 , 953-956.

14 A. N. Roberts, A. C. Cochran, D. A. Rankin, A. B. Lowe and H.-J. Schanz, Organometallics, 2007, 26, 6515-6518.

6015 For a review on ruthenium-indenylidene complexes, see: $(a) \mathrm{F}$. Boeda, H. Clavier and S. P. Nolan, Chem. Commun., 2008, 27262740. For selected references, see: $(b) \mathrm{H}$. Clavier and S. P. Nolan, Chem. Eur. J., 2007, 13, 8029-8036. (c) S. Monsaert, R. Drozdzak, V. Dragutan, I. Dragutan and F. Verpoort, Eur. J. Inorg. Chem.,

65 2008, 432-440. (d) F. Boeda, X. Bantreil, H. Clavier, S. P. Nolan, Adv. Synth. Catal., 2008, 350, 2959-2966. (e) S. Monsaert, E.
DeCanck, R. Drozdzak, P. Van Der Voort, F. Verpoort, J. C. Martins and P. M. S. Hendrickx, Eur. J. Inorg. Chem., 2009, 655-665. (f) H. Clavier, C. A. Urbina-Blanco, S. P. Nolan, Organometallics, 2009 28, 2848-2854.

16 For selected references, see: (a) S. B. Garber, J. S. Kingsbury, B. L. Gray and A. H. Hoveyda, J. Am. Chem. Soc., 2000, 122, 8168-8179. (b) H. Wakamatsu and S. Blechert, Angew. Chem. Int. Ed., 2002, 41, 794-796. (c) K. Grela, S. Harutyunyan and A. Michrowska, Angew. Chem. Int. Ed., 2002, 41, 4038-4040. (d) M. Bieniek, R. Bujok, M. Cabaj, N. Lugan, G. Lavigne, D. Arlt and K. Grela, J. Am. Chem. Soc., 2006, 128, 13652-13653. (e) H. Clavier, F. Caijo, E. Borré, D. Rix, F. Boeda, S. P. Nolan and M. Mauduit, Eur. J. Org. Chem., 2009, 4254-4265.

8017 For selected references, see: (a) E. L. Dias, S. T. Nguyen and R. H. Grubbs, J. Am. Chem. Soc., 1999, 121, 3887-3897. (b) J. A. Love, M. S. Sanford, M. W. Day and R. H. Grubbs, J. Am. Chem. Soc., 2003 , 125, 10103-10109.

18 (a) S. Beligny and S. Blechert in N-Heterocyclic Carbenes in Synthesis, Ed. S. P. Nolan, Wiley-VCH, Weinheim, 2005, pp. 1-25. (b) E. Despagnet-Ayoub and T. Ritter, Top. Organomet. Chem., 2007, 21, 193-218. (c) E. Colacino, J. Martinez and F. Lamaty, Coord. Chem. Rev., 2007, 251, 726-764.

19 (a) M. S. Sanford, J. A. Love and R. H. Grubbs, Organometallics, 2001, 20, 5314-5318. (b) J. A. Love, J. P. Morgan, T. M. Trnka and R. H. Grubbs, Angew. Chem. Int. Ed., 2002, 41, 4035-4037. (c) S. J. P'Pool and H.-J. Schanz, J. Am. Chem. Soc., 2007, 129, 1420014212.

20 (a) M. S. Sanford, L. M. Henling, M. W. Day and R. H. Grubbs, Angew. Chem. Int. Ed., 2000, 39, 3451-3453. (b) J. C. Conrad, H. H. Parnas, J. L. Snelgrove and D. E. Fogg, J. Am. Chem. Soc., 2005, 127, 11882-11883.

21 (a) H. Clavier, K. Grela, A. Kirschning, M. Mauduit and S. P. Nolan, Angew. Chem. Int. Ed., 2007, 46, 6786-6801. (b) M. R. Buchmeiser, Chem. Rev., 2009, 109, 303-326.

22 M. Bieniek, A. Michrowska, D. L. Usanov and K. Grela, Chem. Eur. J., 2008, 14, 806-818.

23 B. Schmidt and J Hermanns, Curr. Org. Chem., 2006, 10, 1363-1396. Of note, in this review, some selectivity issues have been adressed.

10524 B. Schmidt and H. Wildemann, J. Org. Chem., 2000, 65, 5817-5822.

25 L. Jafarpour, M.-P. Heck, C. Baylon, H. M. Lee, C. Mioskowski and S. P. Nolan, Organometallics, 2002, 21, 671-679.

26 D. J. Wallace, J. Mol. Catal. A: Chem., 2006, 254, 78-84.

27 D. J. Wallace, Tetrahedron Lett., 2003, 44, 2145-2148.

11028 A. H. Hoveyda in Handbook of Metathesis, ed. R. H. Grubbs, WileyVCH, Weinheim, 2003, Vol. 2, Chapter 3.

29 (a) T. J. Seiders, D. W. Ward and R. H. Grubbs, Org. Lett., 2001, 3, 3225-3228. (b) T. W. Funk, J. M. Berlin and R. H. Grubbs, J. Am. Chem. Soc., 2006, 128, 1840-1846.

11530 J. M. Berlin, K. Campbell, T. Ritter, T. W. Funk, A. Chlenov and R. H. Grubbs, Org. Lett., 2007, 9, 1339-1342.

31 (a) I. C. Stewart, T. Ung, A. A. Pletnev, J. M. Berlin, R. H. Grubbs and Y. Schrodi, Org. Lett., 2007, 9, 1589-1592. (b) C. K. Chung and R. H. Grubbs, Org. Lett., 2008, 10, 2693-2696.

12032 I. C. Stewart, C. J. Douglas and R. H. Grubbs, Org. Lett., 2008, 10, 441-444.

33 J. A. L. Miles, L. Mitchell, J. M. Percy, K. Singh and E. Uneyama, J. Org. Chem., 2007, 72, 1575-1587.

34 (a) A. Fürstner, L. Ackermann, B. Gabor, R. Goddard, C. W. 125 Lehmann, R. Mynott, F. Stelzer and O. R. Thiel, Chem. Eur. J., 2001, 7, 3236-3253. (b) A. Fürstner, O. R. Thiel and L. Ackermann, Org. Lett., 2001, 3, 449-451.

35 C. W. Lee and R. H. Grubbs, J. Org. Chem., 2001, 66, 7155-7158.

36 M. Donnard, T. Tschanber, S. Desrat, K. Hinsinger and J. Eustache, Tetrahedron Lett., 2008, 49, 1192-1195.

37 (a) A. Fürstner and K. Radkowski, Chem. Commun., 2001, 671-672. (b) A. Fürstner and M. Schlede, Adv. Synth. Catal., 2002, 344, 657665. (c) A. Fürstner, K. Radkowski, C. Wirtz, R. Goddard, C. W. Lehmann and R. Mynott, J. Am. Chem. Soc., 2002, 124, 7061-7069. 135 (d) A. Fürstner T. Nagano, C. Müller, G. Seidel and O. Müller, Chem. Eur. J., 2003, 9, 320-326. 
38 Y. Wu, X. Liao, R. Wang, X.-S. Xie and J. K. De Bradander, J. Am. Chem. Soc., 2002, 124, 3245-3253.

39 Y. Matsuya, S.-i. Takayanagi and H. Nemoto, Chem. Eur. J., 2008, 14, 5275-5281.

50 J. Pospísil, C. Müller and A. Fürstner, Chem. Eur. J., 2009, 15, 59565968.

41 E. C. Hansen and D. Lee, Acc. Chem. Res., 2006, 39, 509-519.

42 (a) T. Kitamura, Y. Sato and M. Mori, Chem. Commun., 2001, 12581259. (b) T. Kitamura, Y. Sato and M. Mori, Adv. Synth. Catal., 2002, 344, 678-693.

43 G. C. Lloyd-Jones, R. G. Margue and J. G. de Vries, Angew. Chem. Int. Ed., 2005, 44, 7442-7447.

44 A. Michrowska, R. Bujok, S. Harutyunyan, V. Sashuk, G. Dolgonos and K. Grela, J. Am. Chem. Soc., 2004, 126, 9318-9325.

1545 V. Sashuk and K. Grela, J. Mol. Catal. A, 2006, 257, 59-66.

46 F. Dolhem, C. Lièvre and G. Demailly, Eur. J. Org. Chem., 2003, 2336-2342.

47 (a) R. Singh, R. R. Schrock, P. Müller and A. H. Hoveyda, J. Am. Chem. Soc., 2007, 129, 12654-12655. (b) Y.-J. Lee, R. R. Schrock and A. H. Hoveyda, J. Am. Chem. Soc., 2009, 131, 10652-10661.

48 H. Clavier, A. Correa, E. C. Escudero-Adán, J. Benet-Buchholz, L. Cavallo and S. P. Nolan, Chem. Eur. J., 2009, 15, 10244-10254.

49 F. Boeda, H. Clavier, M. Jordaan, W. H. Meyer and S. P. Nolan, J. Org. Chem. 2008, 73, 259-263.

2550 F.-D. Boyer, I. Hanna and L. Ricard, Org. Lett., 2001, 3, 3095-3098.

51 C.-J. Wu, R. J. Madhushaw and R.-S. Liu, J. Org. Chem., 2003, 68, 7889-7892.

52 H. Fukumoto, K. Takahashi, J. Ishihara and S. Hatakeyama, Angew. Chem. Int. Ed., 2006, 45, 2731-2734.

3053 M. J. Aldegunde, R. García-Fandiño, L. Castedo, J. R. Granja, Chem. Eur. J., 2007, 13, 5135-5150.

54 M. Movassaghi, G. Piizzi, D. S. Siegel and G. Piersanti, Tetrahedron Lett., 2009, 50, 5489-5492.

55 V. Dragutan and I. Dragutan, J. Orgamet. Chem., 2006, 691, 57295147.

56 B. G. Kim and M. L Snapper, J. Am. Chem Soc., 2006, 128, 52-53.

57 V. Sridharan, S. Maiti and J. C. Menéndez, J. Org. Chem., 2009, 74, 9365-9371.

58 J. Holtsclaw and M. Koreeda, Org. Lett., 2004, 6, 3719-3722.

4059 S. Ma and B. Ni, Chem. Eur. J., 2004, 10, 3286-3300.

60 (a) E. Groaz, D. Banti and M. North, Adv. Synth. Catal., 2007, 349, 142-146. (b) E. Groaz, D. Banti and M. North, Eur. J. Org. Chem., 2007, 3727-3745. (c) E. Groaz, D. Banti and M. North, Tetrahedron, 2008, 64, 204-218.

4561 M. Mori, N. Sakakibara and A. Kinoshita, J. Org. Chem., 1998, 63, 6082-6083.

62 (a) M. Mori, Y. Kuzuba, T. Kitamura and Y. Sato, Org. Lett., 2002, 4, 3855-3858. (b) T. Kitamura, Y. Kuzuba, Y. Sato, H. Wakamatsu, R. Fujita and M. Mori, Tetrahedron, 2004, 60, 7375-7389.

5063 R. J. Spandl, H. Rudyk and D. R. Spring, Chem. Commun., 2008, 3001-3003.

64 D. Banti, E. Groaz and M. North, Tetrahedron, 2004, 60, 8043-8052.

65 A. Behr, A. Westfechtel and J. P. Gomes, Chem. Eng. Technol., 2008, 31, 700-714.

5566 A. F. Newton, S. J. Roe, J.-C. Legeay, P. Aggarwal, C. Gignoux, N. J. Birch, R. Nixon, M.-L. Alcaraz and R. A. Stockman, Org. Biomol. Chem., 2009, 7, 2274-2277.

67 Of note, the two catalysts used in this study might be Cat-1C and Cat-3C and not Cat-1B and Cat-3B as reported

6068 J. L. Bilhou, J. M. Basset, R. Mutin and W. F. Graydon, J. Am. Chem. Soc., 1977, 99, 4083-4090.

69 I. Karamé, M. Boualleg, J.-M. Camus, T. K. Maishal, J. Alauzun, J.M. Basset, C. Copéret, R. J. P. Corriu, E. Jeanneau, A. Mehdi, C. Reyé, L. Veyre and C. Thieuleux, Chem. Eur. J. 2009, 15, 1182011823.

70 A. K. Chatterjee, T.-L. Choi, D. P. Sanders and R. H. Grubbs, J. Am. Chem. Soc., 2003, 125, 11360-11370.

71 J. A. Love, J. P. Morgan, T. M. Trnka and R. H. Grubbs, Angew. Chem. Int. Ed., 2002, 41, 4035-4037.

7072 J. A. Smulik and S. T. Diver, Tetrahedron Lett., 2001, 42, 171-174.

\section{Biographical sketches}

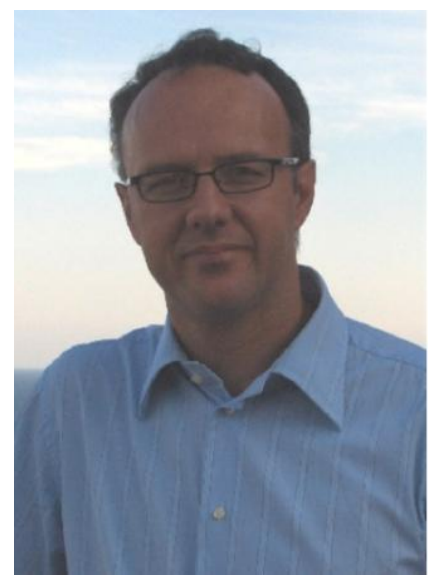

Steven P. Nolan received his B.Sc. in Chemistry from the 75 University of West Florida and his Ph.D. from the University of Miami where he worked under the supervision of Professor Carl D. Hoff. After a postdoctoral stay with Professor Tobin J. Marks at Northwestern University, he joined the Department of Chemistry of the University of New Orleans in 1990. In ${ }_{80}$ 2006, he joined the Institute of Chemical Research of Catalonia (ICIQ) as Group leader and ICREA Research Professor. In early 2009, he joined the School of Chemistry at the University of St Andrews where he holds the Chair of Inorganic Chemistry. His research interests include 85 organometallic chemistry and homogeneous catalysis.

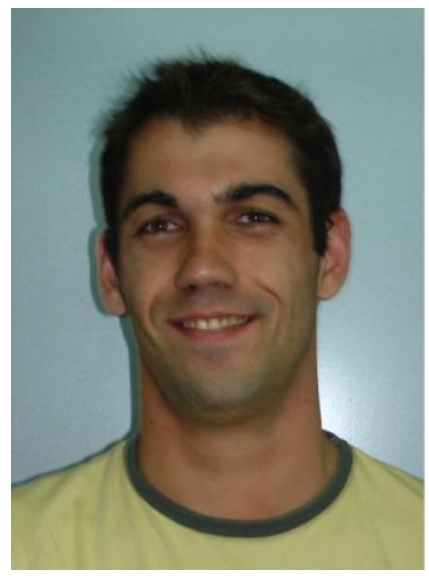

Hervé Clavier graduated from the Ecole Nationale Supérieure de Chimie de Rennes and received his M.Sc. in organic 90 chemistry from the Université de Rennes where he completed his Ph.D. in 2005 under the supervision of Drs Jean-Claude Guillemin and Marc Mauduit. He then joined the research group of Prof. Steven Nolan as a post-doctoral fellow and followed him to the ICIQ in Tarragona. In early 2009, he 95 moved to the School of Chemistry at the University of St Andrews to continue work with Prof. Nolan as a senior researcher and in October 2009, he was appointed Chargé de Recherche (CNRS) at the Université Paul Cézanne, AixMarseille. His scientific interests include catalysis and new 100 synthetic methodologies. 


\section{TOC graphic}

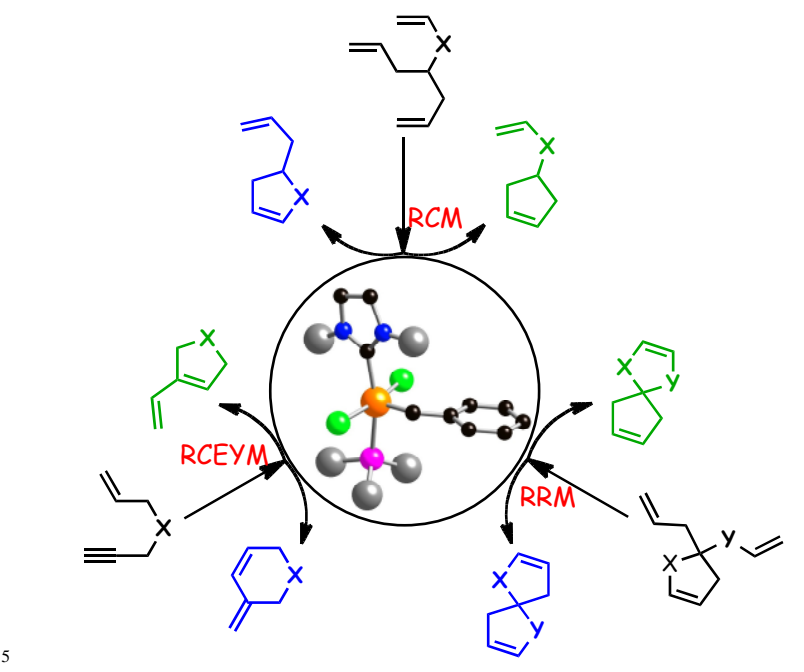

\section{TOC text}

This review provides an overview of studies dealing with chemoselectivity in olefin metathesis and intends to provide 10 an explanation on how the structure of ruthenium-based catalysts can influence the distribution of metathesis products. 